\title{
Measuring the performance of service delivery Systems: with application to software industry and banking in India
}

\author{
Narayan C. Nayak ${ }^{a}$, Ajay K. Behera ${ }^{b *}$, Antaryami Mishra ${ }^{c}$ and Harish C. Das ${ }^{d}$
}

${ }^{a}$ Department of Mechanical Engineering, IGIT Sarang, India

${ }^{b}$ Assistant Professor, Department of Mechanical Engineering, SOA University, India

${ }^{c}$ Professor, Department of Mechanical Engineering, IGIT Sarang, India

${ }^{d}$ Professor, Department of Mechanical Engineering, SOA University, India

\section{CHRON I C L E A B S T RACT}

Article history:

Received: October 1, 2016

Received in revised format: No-

vember 16, 2016

Accepted: March 23, 2017

Available online:

April 14, 2017

Keywords:

Information Technology

Artificial neural network

Feed forward neural architecture

Productivity

Process Management

Retail Banking

\begin{abstract}
This research designs information technology (IT) adoption in service system. It determines the role of IT in determining the performance of service delivery processes. It addresses the concept of IT adoption and discusses the design of the key parameters/elements. Based on a detailed questionnaire survey along with case studies, it outlines how IT can be implemented successfully. Its sole purpose is to help establish whether or not IT adoption improves service quality and firm performance.
\end{abstract}

\section{Introduction}

(C) 2017 Growing Science Ltd. All rights reserved.

Over the last few decades, there has been a change in the Indian banking and software industry due to the adoption of information technology (IT). Indian banks have been offering internet banking services since 2000 to their customers, especially those familiar with IT and have prompt access for banking transactions (Kannabiran \& Narayan, 2005). Throughout the world business firms whether involved in manufacturing of products or delivering service or both recognize quality and performance as two competing factors either to improve or maintain or regain their market share (Nudurupati et al., 2011). However, widespread implementation of IT has become difficult due to lack of infrastructure and low educational background in rural areas in India (Pick et al., 2013).

* Corresponding author

E-mail address: mail2ajaybehera@yahoo.co.in (A. K. Behera) 
A service system consisting of a series of processing stages with information flow provides variety of services as and when required. Service systems are confronted with new pressures in evolving service environment to offer customized services with timely delivery, high quality and more performance (Cui et al, 2003). In addition, IT adopted service system has contributed towards improvement in market share and ability to handle various services (Dewhurst et al, 2003). IT Demand has increased with the development of high bandwidth telecommunications networking and database systems that allow businesses to operate in a global way (Ghobakhloo at al., 2011). Overall performance of service system depends upon many factors (Chang, 2014). During last few years, IT adoption has generated a milestone in banking transactions through the increased use of ATMs in developing countries like India (KPMG, 2015).

Measurement and evaluation standards and procedures for performance of service systems have become practically inconvenient (Tanriverdi, 2005). For systematic assessment of performance, it is desirable to develop a comprehensive methodology to enable the managers and academicians to design an instrument consisting of service dimensions and its related items (Liu et al., 2006). However, researchers have noted that studies on barriers to adoption have been conducted in developed countries (Behera et al., 2015) A typical service system needs to be developed incorporating several IT adoption tools and techniques to ensure its performance in changing environment and market conditions (Mwangi \& Brown, 2015).

Indian banking and software industry have undertaken a number of measures to make ease in various operations (Behera et al., 2015). In addition, the Indian government has passed legislation covering internet banking services. Despite these efforts, service delivery remains a major barrier due to poor IT adoption (Behera et al., 2015). In response to the concerns of Indian banks and software firm, this research presents a development and empirical testing of a model that links the perceived level of performance of service delivery systems to IT adoption (Chen et al., 2012).

The objective of this study is to examine the role of tenure, utility and vendor on IT adoption and ultimately its role on performance of service delivery system. As the pace of development and adoption of new technologies varies between service firms, the type of service is likely to influence the extent of IT adoption.

In the following sections, we discuss review of literature. We then discuss the methodology, analytical results, conclusions and recommendations of our findings.

\section{Literature review and hypotheses}

Previous literature addresses the importance of IT adoption in the success of service firms. However, a close look at the literature reveals that there is no common agreement among the authors on even the definition of IT adoption, IT adoption equipment, service system design, service quality, and system performance. In the era of e-Banking, IT-based systems are able to handle core-banking functionalities (Peter at al., 2011). Banks are motivated to incorporate IT literacy skills among the existing bank staff to enhance performance (Lepmets et al., 2014). Bank employee with IT knowledge caters banking services as per the customer requirements (Hawari \& Ward, 2006). With the incorporation of IT, there is ample opportunity enabling organizations to succeed financially (Doha et al., 2014).

Researchers and practitioners have proposed a number of models and methodologies for measuring and evaluating firm performance (Igbaria \& Tan, 1997). Those models address operational and financial aspects (Mikhailov \& Tsvetinov, 2004). Strategies of IT adoption are required to measure system performance (Goo, 2010). The studies on the relationship between IT adoption and effectiveness are conducted in either of the two ways: empirically finding out the relationships in a given service system or 
proposing an analytical/mathematical model of these relationships (Yee et al., 2013). A few investigators have reported empirical relationships between specific IT adoption and performance dimensions (Zhang et al., 2007; Parka et al., 2012). The hypothesis can be formulated as:

\section{$H_{1}:$ IT adoption has significant positive effect on effectiveness}

In service sector, IT adoption process is directly affected by top management where all decisions from daily functions to future investments are made by them. Knowledge and experience of CEO are important factors for affecting IT adoption (Ghobakhloo et al., 2010). The study revealed that, the role of CEOs (top management, owner) affect activities, both in current and in future (Durdyeva et al., 2014; Davis, 1989). The study has found that there is a negative impact on business productivity due to lack of sufficient IT user employees (Southern \& Tilley, 2000). Performance of service system depends upon many factors, namely, level of IT service quality, customer attitude towards IT usage, customer satisfaction, and operational efficiency (Bruque \& Moyano, 2007). Thus, it can be hypothesized as follows:

\section{$H_{2}$ : IT adoption has significant positive effect on efficiency}

Online finance introduced by bank leverage its state of the art technology for the convenience of customers (Jayawardhana, 2004). Online financing has been established under Supply Chain Finance Unit (Shaik and Abdul, 2014). Apart from the traditional banking business, banks have been strengthened to produce variety of financial and non-financial activities (Bergendahl \& Lindblom, 2008). Technological change has been accepted by the Bankers (Arasli, 2005). Automated customer care and selfservice are the main cause to reduce costs and handle an ever-increasing number of transactions (Therrien at al., 2011). Due to the changing demand, customers are not dependent on a single communication device (Chan \& Ngai, 2010). In the shifting paradigm, customers can be expected anytime, anywhere access to services (Gustafsson et al., 2003). Thus, the effect of IT on productivity has been hypothesized:

\section{H3: IT adoption has significant positive effect on productivity}

\section{Methodology}

A questionnaire in the form of a survey instrument was developed using the total design method (Jun \& Cai, 2010). Survey items were collected from previously published studies. The objective of questionnaire was to elicit the opinion of the respondents on the importance of the need and effectiveness related factors (Vera \& Trujillo, 2013). The questionnaire at the initial stage was sent to selected persons for pretesting. Pilot test was done for survey instrument and selected persons were included (Table 1). Modifications were made wherever necessary and unreliable items were eliminated where ten subject matter experts conducted a Q-sort analysis (Hussain \&d Gunasekaran, 2002). Then, the final version of the questionnaire was designed. A database was created by selecting all leading service industries. The sample firms defined in the database are randomly selected.

\section{Table 1}

Distribution and Composition of Panelists

\begin{tabular}{lcc}
\hline Category & No. of persons contacted & No. of respondents \\
\hline Executives from Industry & 30 & 19 \\
Professors and Researchers & 18 & 11 \\
\hline Total & 48 & 30 \\
\hline
\end{tabular}

\subsection{Survey Design}

The target population for this research was selected from Indian Bank and IT firms. By using the nonprobability sampling technique, a scientific stratified sampling scheme was implemented. The research 
analysis was from a single branch or unit. The respondents were related with IT activities. In 2015, managers from various departments in the banking and software firm with IT expertise whose standard Industrial classification codes were 7371 (software firms) and 6021 (Nationalized commercial Banks) were included as respondent titles. Stratified sampling has several potential benefits (Carmeli et al., 2008). 125 completed surveys were returned from 500 surveys that were mailed, with a response rate of 25 percent. Units having 51 to 100 employees corresponds 40\%, between 101- 200 employees 30\%, and more than 200 employees rest 30\%. Banking (48 percent) and IT firms (52 percent) were the respondents from the sample. ANOVA (analysis of variance) was carried out across the two service sectors and non-response bias was assessed by comparing general characteristics of non-responding firms (Therrien et al., 2011). No differences were detected. Table 2 represents frequency distribution of responding firms.

Table 2

Frequency distribution of responding firms

\begin{tabular}{lccc}
\hline SIC Code & Firms Approached & Responses Received & Percentage \\
\hline SIC 6021 & 300 & 60 & 48 \\
SIC 7371 & 200 & 65 & 52 \\
\hline Total & 500 & 125 & 100 \\
\hline
\end{tabular}

\subsection{Dependent variables}

A set of variables were considered to measure performance of service system. Effectiveness is the degree of achievement of the functional values of services indicative of the purpose of doing business for which goals and objectives are set and activities are performed. An efficient system either requires fewer inputs or delivers more outputs compared to a similar system. It refers to the volume of output achieved for the internal resources consumed. Productivity is the ability of a service organization to use its inputs for providing services with quality matching the expectation of customers. Effectiveness, efficiency and productivity are described in Table 3.

\section{Table 3}

Variables used to measure firm performance

\begin{tabular}{ll}
\hline & \multicolumn{1}{c}{ Effectiveness } \\
\hline i & Software installation is easy \\
ii & Installation is accurate and complete \\
iii & Installed software functions without problems or errors \\
\hline iv & Installed software functions without service interruptions or crashes \\
v & Installed software functions without problems or errors in long run basis \\
\hline vi & Installed software after updating, functions without service interruptions \\
\hline & $\quad$ Efficiency \\
\hline i & Using the software, tasks are easily performed \\
ii & Software completeness in all aspects quickly finishes the task \\
\hline iii & Availability of technical support for completion of different task \\
\hline iv & Completeness of user documentation requires less work force \\
\hline v & Completeness in employee training produces more man hour \\
vi & Software developed in-house is of satisfaction and performs task accurately \\
\hline & $\quad$ Productivity \\
\hline i & Compatibility of using the software \\
ii & Comparison of own software to other similar software for same task \\
iii & Ability of technical support to solve user problems \\
\hline iv & Documentation usefulness to complete variety of task \\
\hline v & Training usefulness to complete the required task \\
vi & Overall, how useful are the own software products for support services \\
\hline Independent variables
\end{tabular}

Survey items of IT adoption to measure system performance are presented in Table 4. 
Table 4

Variables used for IT usage

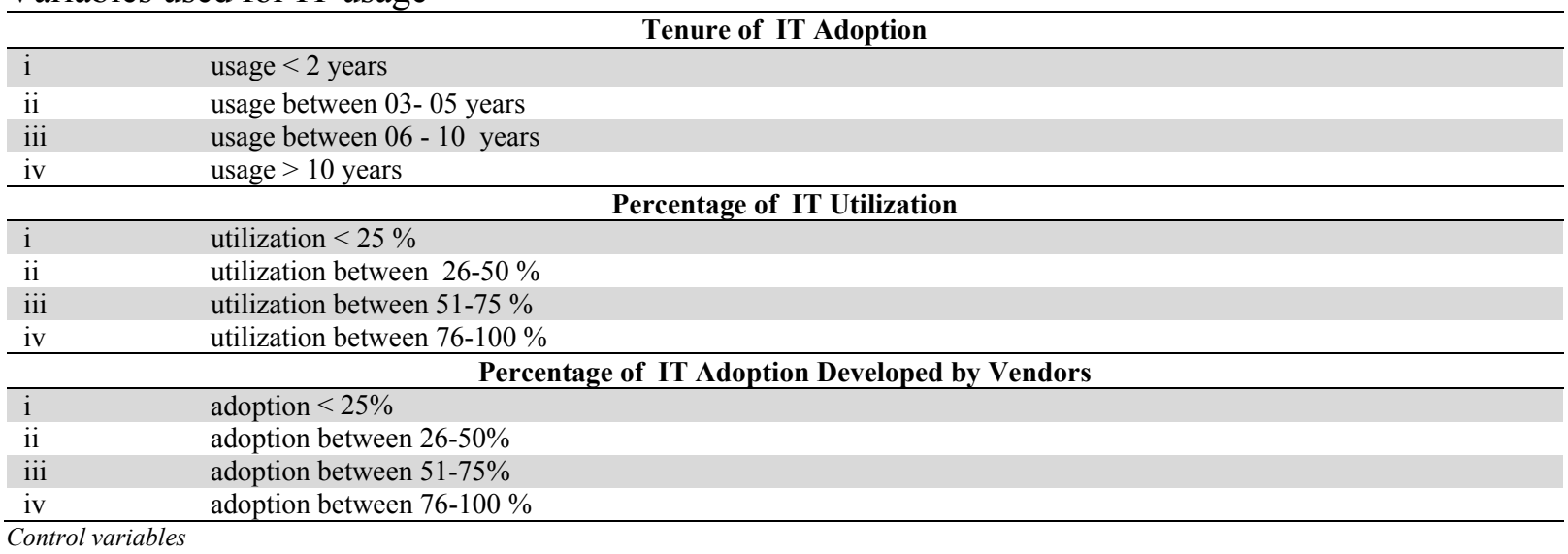

Fig. 1 shows the ANN model relating input parameters (tenure of IT adoption, utility of IT adoption, and vendor support for IT adoption) and output parameters (efficiency, effectiveness and productivity) for service system performance. There exists one hidden layer in the model.

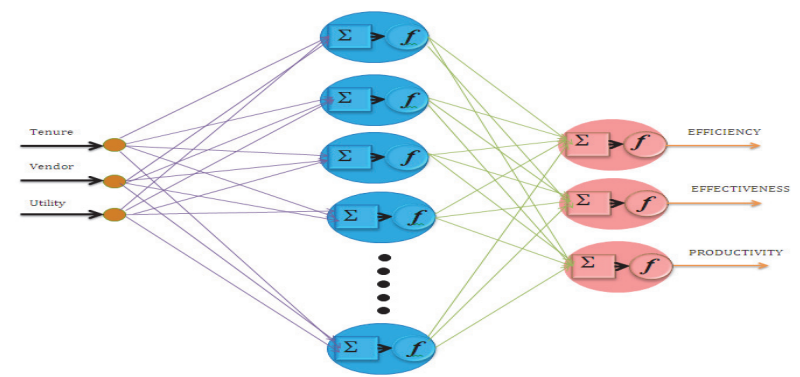

Fig. 1. ANN model for relating IT adoption and system performance

\section{Analysis of Results}

Based upon the optimal validation performance, training $\mathrm{R}$ and validation $\mathrm{R}$ values, different process parameters are chosen and documented. Based upon the optimal parameter value, final model has been developed. Various values of neural network model which has been used in the final mapping of IT adoption and performance are provided in Table 5. Neural network modelling has been performed using MATLAB 2011b.

\section{Table 5}

Optimal process parameter setting of Feed Forward Neural Architecture (FFNA)

\begin{tabular}{|c|c|c|c|}
\hline $\begin{array}{l}\text { Sl. } \\
\text { No. }\end{array}$ & Parameter & Data and its range & Technique and type of parameter used \\
\hline 01 & Neural architecture & - & FFNA \\
\hline 02 & Number of input neurons & 3 (tenure, utility and vendor) & - \\
\hline 03 & No. of output neurons & 3 (performance measures) & - \\
\hline 04 & Total no. of exemplars & 125 & - \\
\hline 05 & Number of hidden layer & 01 & - \\
\hline 06 & $\begin{array}{l}\text { Ratio of training, validation and testing of } \\
\text { data }\end{array}$ & $80: 10: 10$ & - \\
\hline 07 & Normalization of data & 0.05 to 0.95 & Min-max data normalization technique \\
\hline 08 & Initialization of weight & -0.5 to 0.5 & Random wt. initialization \\
\hline 09 & Transfer function/ Activation function & $\begin{array}{l}0 \text { and } 1 \text { for logsig and }-1 \text { to } 1 \text { for tan- } \\
\text { sig }\end{array}$ & $\begin{array}{c}\text { Logsig for hidden Layer \& tansig for output } \\
\text { Layer }\end{array}$ \\
\hline 10 & Error function & - & Mean squared error function \\
\hline 11 & Training Algorithm & - & Levenberg-Marquardt back propagation type \\
\hline 12 & Mode of training & - & Batch mode \\
\hline 13 & Type of learning rule & - & Supervised learning rule \\
\hline 14 & Stopping criteria & - & Early stopping \\
\hline
\end{tabular}


Choosing number of hidden Layer and transfer function / activation function:

To select the best hidden layer and transfer/activation function, ANN modelling was performed for performance measures. Several variations of FFNA have been considered and documented in Table 6:

\section{Table 6}

Variation of Process Parameters of Feed Forward Neural Architecture (FFNA)

\begin{tabular}{llcc}
\hline Sl. No. & Parameters & Type of parameter & Data or range of data \\
\hline 01 & Hidden layer & NA & $1,2,3$ \\
02 & Hidden Neuron & NA & 8,16 \\
03 & Transfer function/ Activation function & Tansig, logsig, purelin \& hardlim & NA \\
\hline
\end{tabular}

Based upon the values of optimal validation performance, training $\mathrm{R}$ and validation $\mathrm{R}$, different process parameters for ANN model was obtained. It was found that FFNA performs better than Elman and Layer Recurrent models. In the sub sections below, effect of IT adoption upon various performance measures (effectiveness, efficiency and productivity) are discussed:

\section{Case - 1: Effectiveness}

Effect of tenure of IT adoption, utility of IT and vendor contribution upon effectiveness of performance was carried out. Table 7 shows the process parameter setting and Evaluation parameters of Neural Architecture i.e., Validation Performance, Training R and Validation R. it is observed that single hidden layer provides the optimum results rather than multiple layers. Fig. 2 and Fig. 3 show the Main Effects Plot for Validation Performance and Main Effects Plot for Training R respectively.

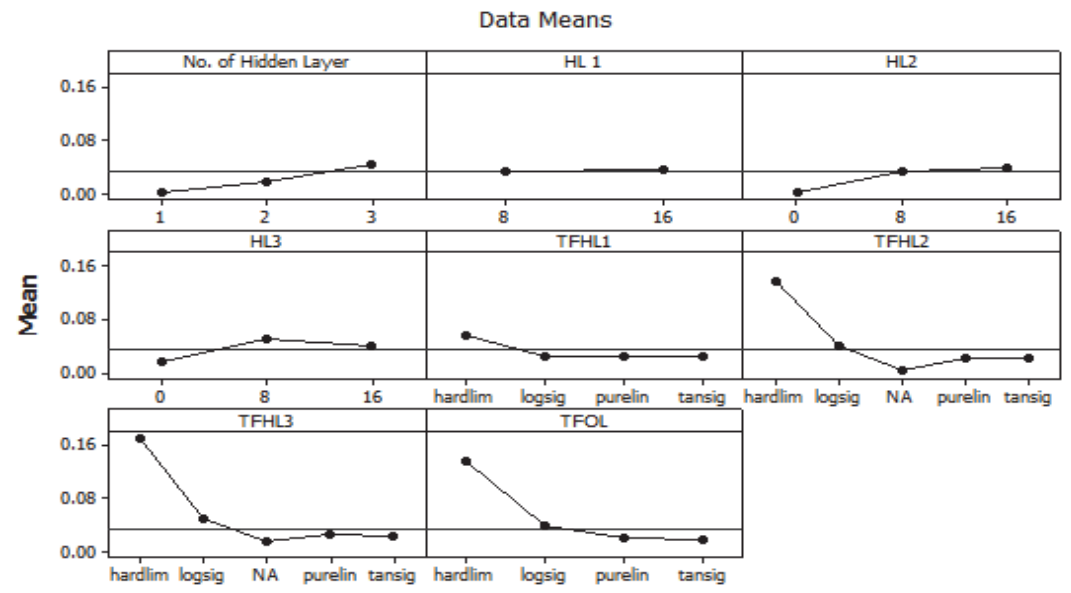

Fig. 2. Main Effects Plot for Validation Performance

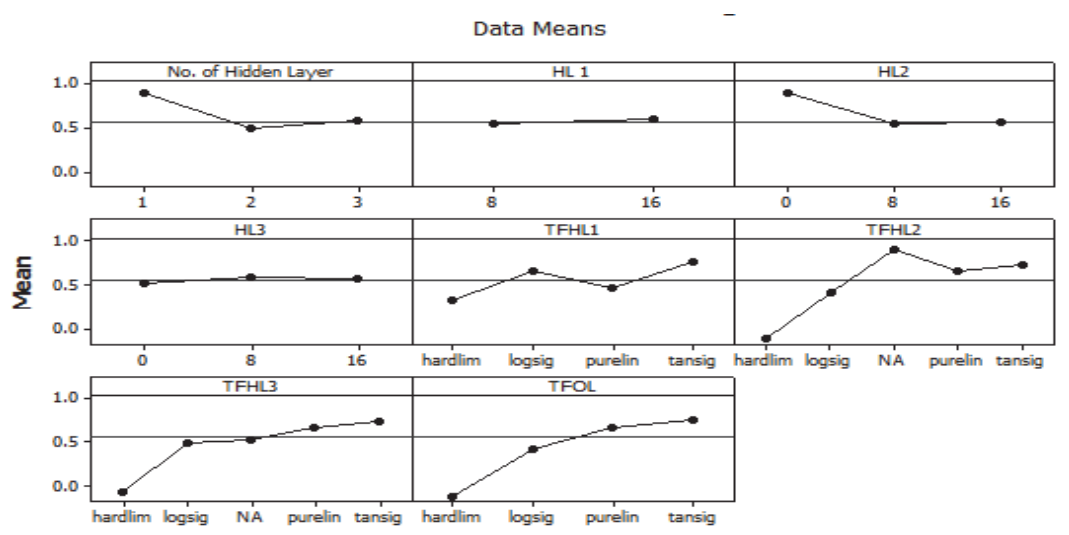

Fig. 3. Main Effects Plot for Training R 
Table 7

FFNA modelling of Effectiveness

\begin{tabular}{|c|c|c|c|c|c|c|c|c|c|c|}
\hline \multirow{2}{*}{$\begin{array}{l}\text { No. of } \\
\text { Hidden } \\
\text { Layer }\end{array}$} & \multicolumn{3}{|c|}{ No. of Hidden Neurons } & \multicolumn{4}{|c|}{ Name of the Transfer function } & \multicolumn{3}{|c|}{ Evaluation of Neural Architecture } \\
\hline & HL 1 & HL2 & HL3 & HL1 & HL2 & HL3 & Output Layer & $\begin{array}{l}\text { Validation Per- } \\
\text { formance }\end{array}$ & Training R & Validation $\mathrm{R}$ \\
\hline 1 & 16 & 0 & 0 & $\operatorname{logsig}$ & NA & NA & tansig & 0.0022182 & 0.89786 & 0.85305 \\
\hline 2 & 8 & 8 & 0 & $\operatorname{logsig}$ & tansig & NA & tansig & 0.027104 & 0.74344 & 0.76261 \\
\hline 2 & 8 & 8 & 0 & $\operatorname{logsig}$ & logsig & NA & logsig & 0.012225 & 0.18333 & 0.24908 \\
\hline 2 & 8 & 8 & 0 & $\operatorname{tansig}$ & tansig & NA & tansig & 0.0057705 & 0.82156 & 0.74587 \\
\hline 2 & 8 & 8 & 0 & tansig & logsig & NA & logsig & 0.017645 & 0.60001 & 0.35024 \\
\hline 2 & 8 & 8 & 0 & purelin & purelin & NA & purelin & 0.016187 & 0.43335 & 0.57315 \\
\hline 2 & 8 & 8 & 0 & logsig & purelin & NA & purelin & 0.0069375 & 0.83589 & 0.86004 \\
\hline 2 & 8 & 8 & 0 & $\operatorname{tansig}$ & purelin & NA & purelin & 0.0038725 & 0.82706 & 0.68007 \\
\hline 2 & 8 & 8 & 0 & hardlim & hardlim & NA & hardlim & 0.068579 & -0.1771 & -0.13885 \\
\hline 2 & 8 & 8 & 0 & hardlim & logsig & NA & logsig & 0.021934 & 0.00442 & 0.27947 \\
\hline 2 & 8 & 8 & 0 & hardlim & tansig & NA & tansig & 0.00629 & 0.60048 & 0.27669 \\
\hline 2 & 8 & 8 & 0 & hardlim & purelin & NA & purelin & 0.01283 & 0.54185 & 0.12905 \\
\hline 3 & 8 & 8 & 8 & $\log \operatorname{sig}$ & tansig & $\operatorname{tansig}$ & tansig & 0.016268 & 0.78148 & 0.83601 \\
\hline 3 & 8 & 8 & 8 & $\operatorname{logsig}$ & logsig & logsig & logsig & 0.048635 & 0.55828 & 0.12016 \\
\hline 3 & 8 & 8 & 8 & $\operatorname{tansig}$ & tansig & tansig & tansig & 0.022506 & 0.85502 & 0.66007 \\
\hline 3 & 8 & 8 & 8 & $\operatorname{tansig}$ & logsig & logsig & logsig & 0.040534 & 0.84533 & 0.021823 \\
\hline 3 & 8 & 8 & 8 & purelin & purelin & purelin & purelin & 0.017976 & 0.51575 & 0.48662 \\
\hline 3 & 8 & 8 & 8 & $\operatorname{logsig}$ & purelin & purelin & purelin & 0.020645 & 0.78122 & 0.7259 \\
\hline 3 & 8 & 8 & 8 & $\operatorname{tansig}$ & purelin & purelin & purelin & 0.037222 & 0.73547 & 0.43607 \\
\hline 3 & 8 & 8 & 8 & hardlim & hardlim & hardlim & hardlim & 0.28193 & -0.1885 & -0.04394 \\
\hline 3 & 8 & 8 & 8 & hardlim & logsig & $\log \operatorname{sig}$ & logsig & 0.033911 & 0.35464 & -0.38258 \\
\hline 3 & 8 & 8 & 8 & hardlim & tansig & tansig & tansig & 0.020697 & 0.61618 & 0.61917 \\
\hline 3 & 8 & 8 & 8 & hardlim & purelin & purelin & purelin & 0.006463 & 0.57029 & 0.77994 \\
\hline 3 & 16 & 16 & 16 & $\operatorname{logsig}$ & tansig & tansig & tansig & 0.038317 & 0.65012 & 0.80716 \\
\hline 3 & 16 & 16 & 16 & $\operatorname{logsig}$ & logsig & $\operatorname{logsig}$ & logsig & 0.0608 & 0.50018 & 0.82947 \\
\hline 3 & 16 & 16 & 16 & $\operatorname{tansig}$ & tansig & $\operatorname{tansig}$ & tansig & 0.020156 & 0.76911 & 0.38613 \\
\hline 3 & 16 & 16 & 16 & tansig & logsig & logsig & logsig & 0.039306 & 0.65394 & 0.72292 \\
\hline 3 & 16 & 16 & 16 & purelin & purelin & purelin & purelin & 0.038302 & 0.47148 & 0.88143 \\
\hline 3 & 16 & 16 & 16 & $\operatorname{logsig}$ & purelin & purelin & purelin & 0.013901 & 0.67901 & 0.65135 \\
\hline 3 & 16 & 16 & 16 & $\operatorname{tansig}$ & purelin & purelin & purelin & 0.026841 & 0.82076 & 0.52915 \\
\hline 3 & 16 & 16 & 16 & hardlim & hardlim & hardlim & hardlim & 0.059187 & 0.04862 & 0.00111 \\
\hline 3 & 16 & 16 & 16 & hardlim & logsig & logsig & logsig & 0.070126 & 0.06785 & 0.54197 \\
\hline 3 & 16 & 16 & 16 & hardlim & tansig & $\operatorname{tansig}$ & tansig & 0.028457 & 0.76457 & 0.51093 \\
\hline 3 & 16 & 16 & 16 & hardlim & purelin & purelin & purelin & 0.040067 & 0.7715 & -0.07466 \\
\hline
\end{tabular}

Using statistical methods and SPSS software, data collected from questionnaire have been analyzed. The effect of IT on service performance was checked. Using confidence level of $95 \%$ (significance level of $\alpha=0.05$ ), the analysis of variance (ANOVA) was carried out. Tenure of IT adoption, utility of IT and vendor contribution upon effectiveness of service system performance has been modeled. Results obtained from ANOVA have been verified with that of ANN modeling. Effectiveness linearly increases with tenure and utility (Fig. 4 (a), 4 (b)). However, vendor does not have significant effect on performance (Fig. 4 (c)).

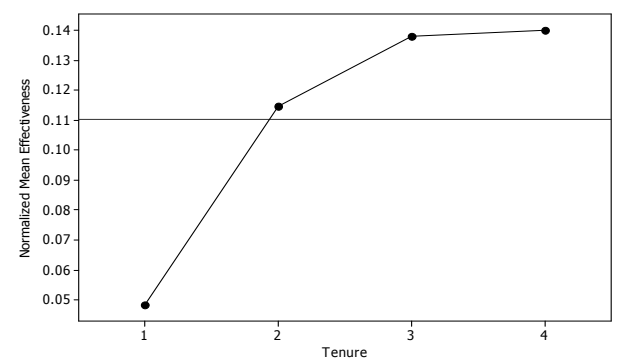

Fig. 4 (a). Tenure vs. Effectiveness

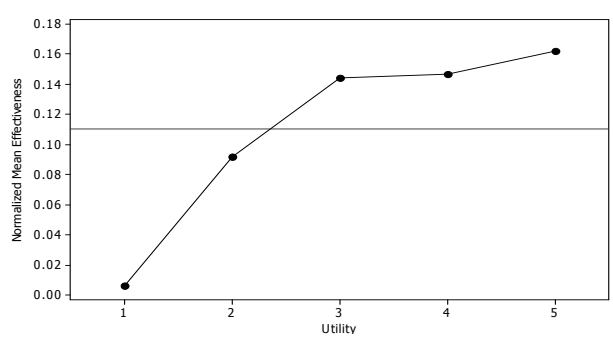

Fig. 4 (b). Utility vs. Effectiveness 


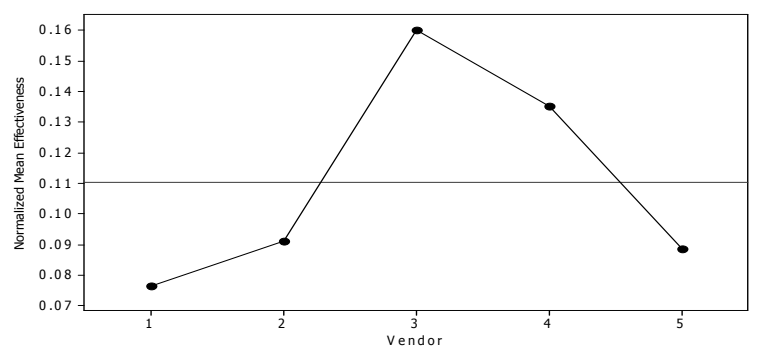

Fig. 4 (c). Vendor developed IT service vs. Effectiveness

\section{Case - 2: Efficiency}

Process parameter setting and evaluation parameters (Validation Performance, Training R and Validation R) have been obtained using FFNA modeling, as in Table 7. Figure 5 and 6 show the Main Effects Plot for Training R and Main Effects Plot for Validation Performance respectively.

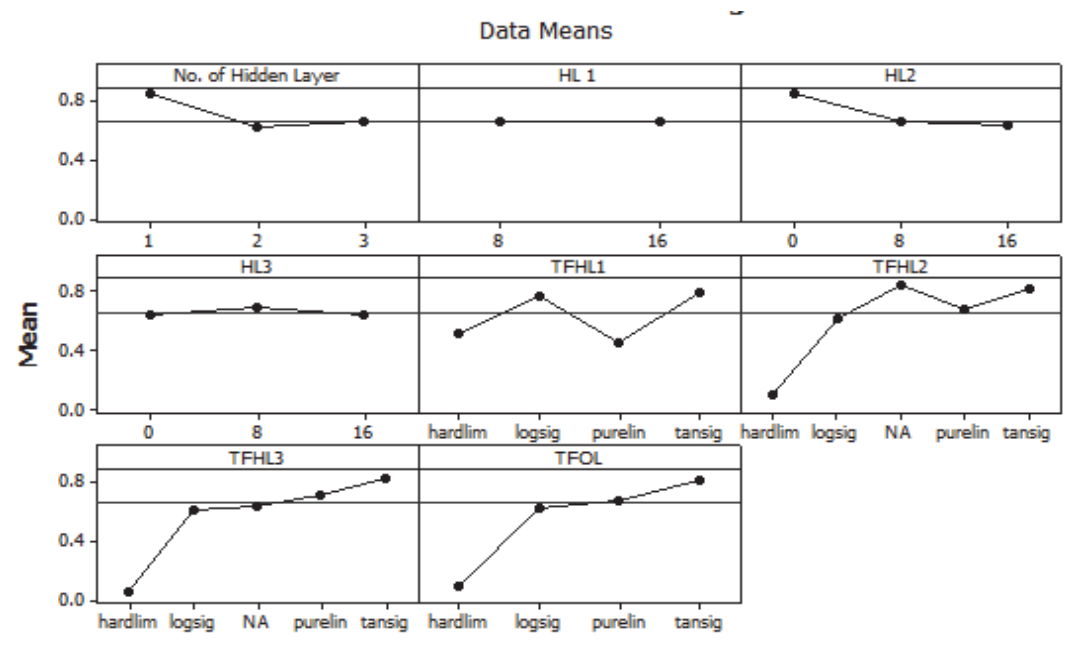

Fig. 5. Main Effects Plot for Training R

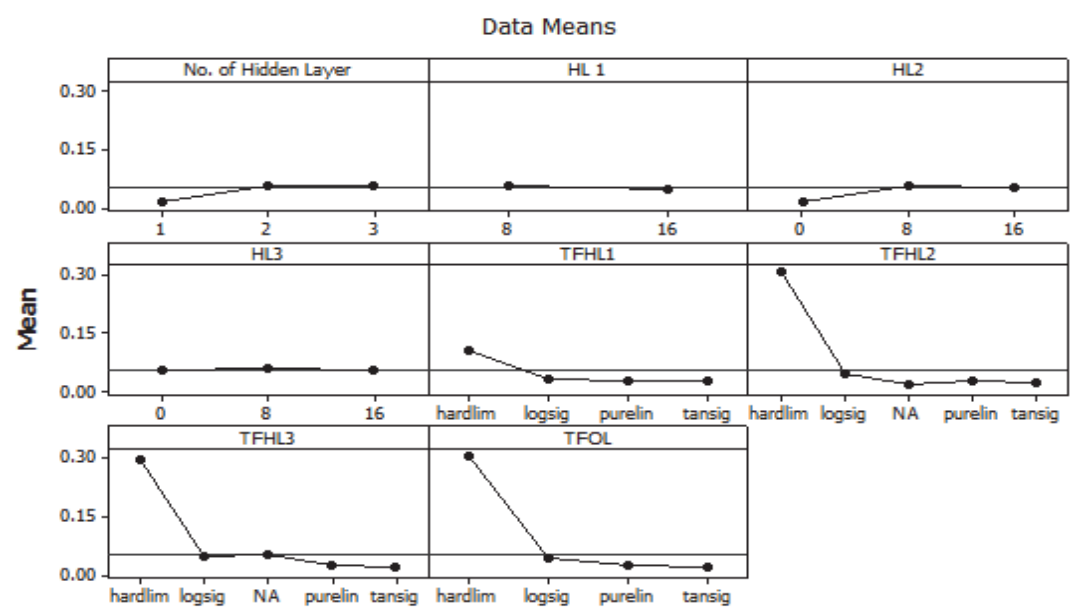

Fig. 6. Main Effects Plot for Validation Performance 
Tenure of IT adoption, utility of IT and vendor contribution upon efficiency has been modeled. Results obtained from ANN model have been verified with that of ANOVA. Efficiency increases with increase in tenure and utility of IT service (Figs. 7 (a), (b)). However, vendor plays no role (Fig. 7 (c)). Thus more the IT service being utilized, more will be the firm's efficiency.

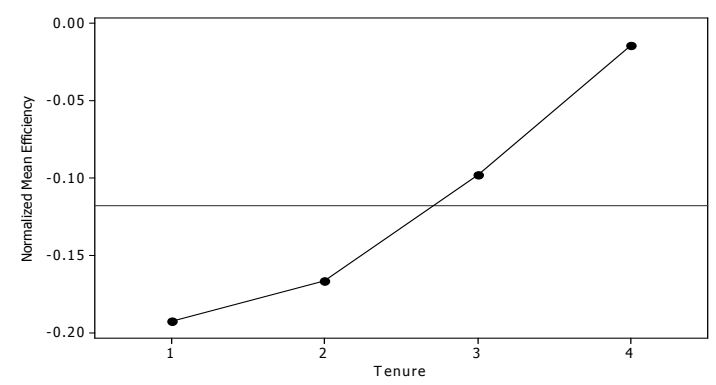

Fig. 7 (a). Tenure vs. Efficiency

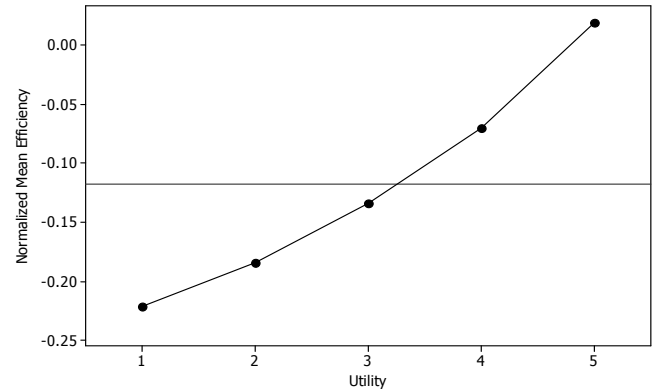

Fig. 7 (b). Utility vs. Efficiency

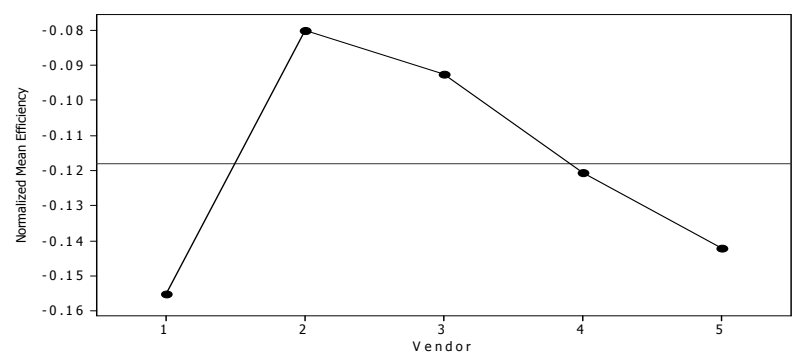

Fig. 7 (c). Vendor developed IT service vs. Efficiency

\section{Case - 3: Productivity}

Using FFNA modeling, Validation Performance, Training $\mathrm{R}$ and Validation $\mathrm{R}$ values for process parameter setting and evaluation parameters have been obtained, as in Table 7 . Figure 8 and 9 shows the Main Effects Plot for Training R and Validation Performance respectively.

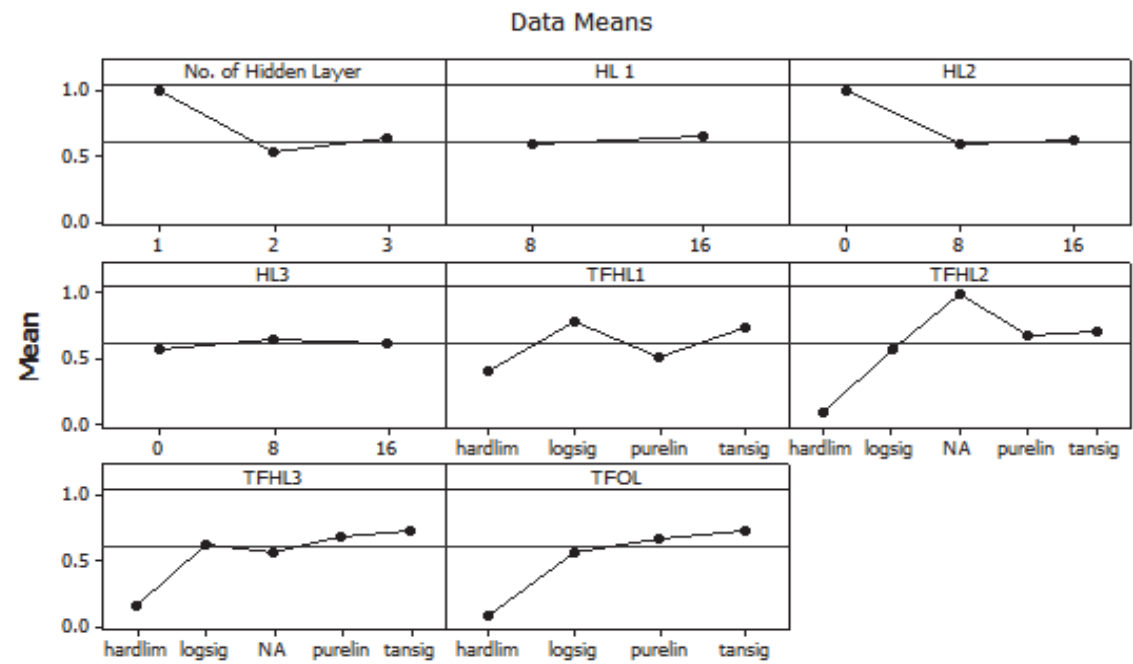

Fig. 8. Main Effects Plot for Training R 


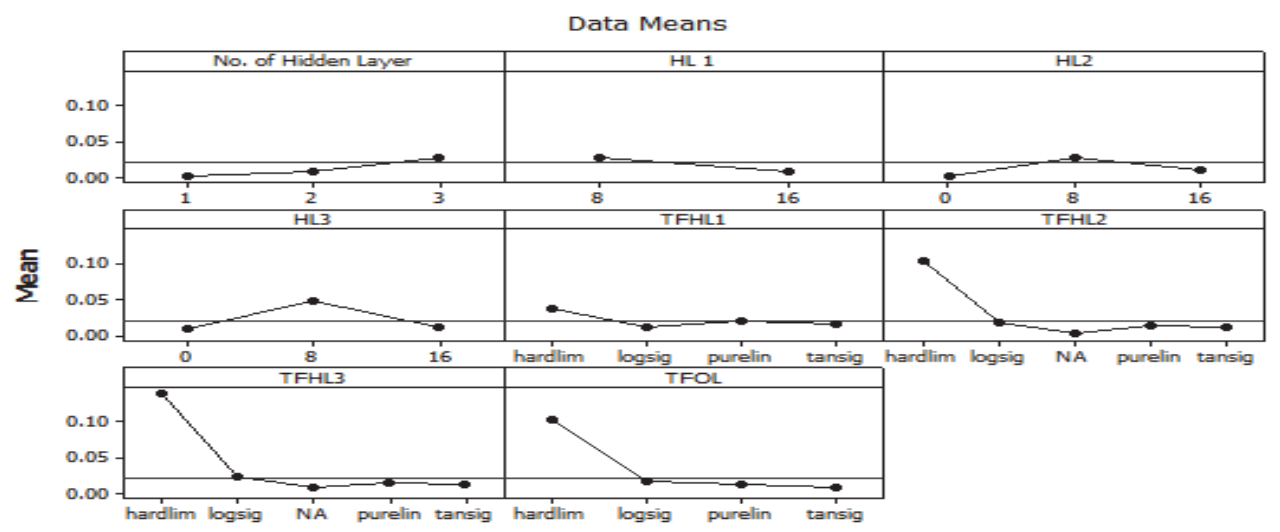

Fig. 9. Main Effects Plot for Validation Performance

Tenure of IT adoption, utility of IT and vendor contribution upon productivity improvement of firm has been modeled. Results obtained from statistical analysis using ANOVA have been verified with that of ANN model. Productivity increases with tenure (Fig. 10 (a)) and utility (Fig. 10 (b)). Vendor does not have any significant role for enhancing the productivity of system (Fig. 10 (c)).

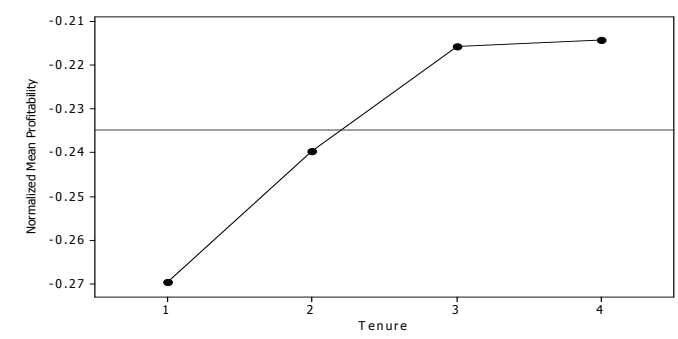

Fig. 10 (a). Tenure vs. Productivity

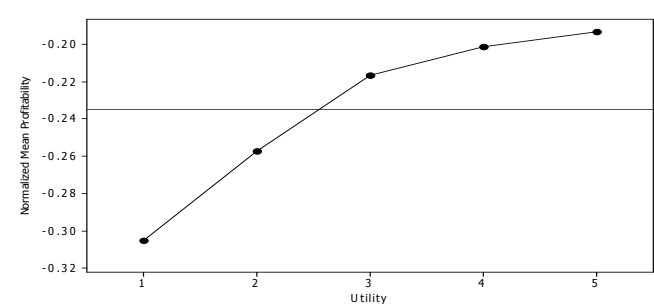

Fig. 10 (b). Utility vs. Productivity

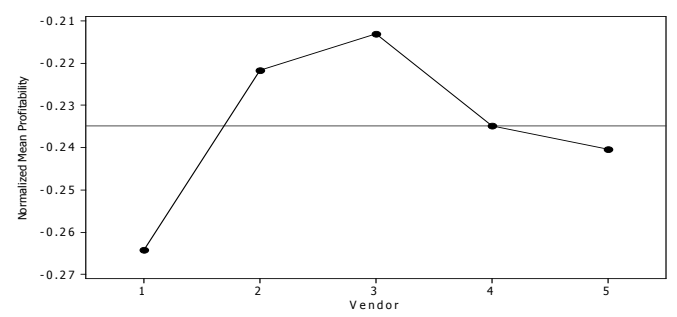

Fig. 10 (c). Vendor developed IT service vs. Productivity

\section{Conclusions and recommendations for future research}

Normal probability plot for effectiveness, efficiency and productivity were drawn for residuals. It confirms the normal distribution of the data as the graph approaches linearity. Relationship between predicted values and standardized residuals were also checked. It has been observed that, data were distributed in both positive and negative directions and concluded that the model was adequate having no cause to think about violation of the constant variance assumption or independence. Histogram for all the above cases were drawn and all reflects uniform distribution around ' 0 ' (mean value) and shows conformance of the constant variance of the entire data, plotted between standard residual and observation order. 
After analyzing the result of Training $\mathrm{R}$ and Validation Performance from the obtained Main Effect Plots and the tabulated results of various FFNA modelling for all the performance measures, it can be concluded that the process parameter setting of FFNA (transfer function, number of hidden layer, number of hidden neurons) that has been tabulated in Table 5 is optimal. With the help of specified process parameters in the above table, final neural network model has been developed. With varying hidden layers and learning parameter, the following observations were made:

i) Changing the hidden layers and also the learning parameter there will be a variation in performance of ANN model, and the same has been demonstrated. It is concluded that single hidden layer with 16 numbers of neuron gives the best result for performance.

ii) The appropriate transfer function found from above analysis for hidden layer is logsig and for output layer is tansig, which has been implemented in the final model.

iii) In neural network modelling, increasing the inputs will have impact. In this research, the number of input variable remains same for all the performance measures.

Performance of ANN model is mainly dependent upon the type of neural architecture, number of hidden neurons, number of hidden layers, and type of transfer/activation function. In order to build up an efficient ANN model, the focus has been given on the above critical parameters. However, increasing the number of outputs in network, will not affect the performance of the developed ANN model as the modelling has been done with optimal process parameter setting.

\subsection{Bivariate Correlations}

In order to examine the bivariate relationship, scatter plots have been formed. It has been observed that the corresponding joint values of the variables lie along a straight line, thus a linear relationship or correlation exists. No combination seems to exhibit a non linear relationship that would not be represented in a bivariate correlation.

\subsection{Testing the Hypotheses}

The model developed for establishing relationship between IT adoption and performance is applied in banks as well as software firms. Both the input variable tenure and utility bears significant positive relationship with service system performance. However, vendor bears no relationship with performance. The application of the methodology has been found to result in better understanding than that of the existing methodologies relating IT adoption - performance.

\subsection{Directions for Future Research}

Author identifies the following few important areas, that need further study: (i) consideration of other 'intangible' factors, (ii) Contribution of resources, effect of intellectual apathy, leadership quality, (iii) Other services such as, hospital, hotel, airline, education may be taken into account, and (iv) Development of suitable IT adoption and evaluation model for production firms.

\section{Acknowledgement}

The authors would like to thank the anonymous referees for constructive comments on earlier version of this paper. 


\section{References}

Arasli, H., Turan Katircioglu, S., \& Mehtap-Smadi, S. (2005). A comparison of service quality in the banking industry: Some evidence from Turkish-and Greek-speaking areas in Cyprus. International Journal of Bank Marketing, 23(7), 508-526.

Behera, A. K., Nayak, N. C., \& Das, H. C. (2015). Performance Measurement in Banking \& Software Firm: An Empirical Research. Global Journal of Flexible Systems Management, 16(1), 3-18.

Behera, A. K., Nayak, N. C., Das, H. C., \& Mohapatra, R. N. (2015). An empirical study of the impact of IT on performance in Indian service industries. Global Business and Organizational Excellence, 34(3), 67-78.

Behera, A., Nayak, N., \& Das, H. (2015). Performance measurement due to IT adoption. Business Process Management Journal, 21(4), 888-907.

Bergendahl, G., \& Lindblom, T. (2008). Evaluating the performance of Swedish savings banks according to service efficiency. European Journal of Operational Research, 185(3), 1663-1673.

Behera, A. K., Nayak, N. C., \& Das, H. C. (2015). Performance measurement in banking \& software firm: An empirical research. Global Journal of Flexible Systems Management, 16(1), 3-18.

Bruque, S., \& Moyano, J. (2007). Organisational determinants of information technology adoption and implementation in SMEs: The case of family and cooperative firms. Technovation, 27(5), 241-253.

Carmeli, A., Sternberg, A., \& Elizur, D. (2008). Organizational culture, creative behavior, and information and communication technology (ICT) usage: A facet analysis. CyberPsychology \& Behavior, 11(2), 175-180.

Chan, H. C., \& Ngai, E. W. T. (2010). What makes customers discontent with service providers? An empirical analysis of complaint handling in information and communication technology services. Journal of business ethics, 91(1), 73-110.

Chang, T. H. (2014). Fuzzy VIKOR method: a case study of the hospital service evaluation in Taiwan. Information Sciences, 271, 196-212.

Chen, J. S., \& Tsou, H. T. (2012). Performance effects of IT capability, service process innovation, and the mediating role of customer service. Journal of Engineering and Technology Management, 29(1), 71-94.

Chi Cui, C., Lewis, B. R., \& Park, W. (2003). Service quality measurement in the banking sector in South Korea. International Journal of Bank Marketing, 21(4), 191-201.

Davis, F.D. (1989). Perceived usefulness, perceived ease of use, and user acceptance of information technologies. MIS Quarterly, 13(3), 319-340.

Dewhurst, F. W., Rafael Martínez-Lorente, A., \& Sánchez-Rodríguez, C. (2003). An initial assessment of the influence of IT on TQM: a multiple case study. International Journal of Operations \& Production Management, 23(4), 348-374.

Ojha, D., Salimath, M., \& D'Souza, D. (2014). Disaster immunity and performance of service firms: The influence of market acuity and supply network partnering. International Journal of Production Economics, 147, 385-397.

Durdyev, S., Ihtiyar, A., Ismail, S., Ahmad, F. S., \& Bakar, N. A. (2014). Productivity and service quality: Factors affecting in service industry. Procedia-Social and Behavioral Sciences, 109, 487491.

Ghobakhloo, M., Zulkifli, N. B., \& Aziz, F. A. (2010). The interactive model of user information technology acceptance and satisfaction in small and medium-sized enterprises. European Journal of economics, finance and administrative sciences, 19(1), 7-27.

Ghobakhloo, M., Benitez-Amado, J., \& Arias-Aranda, D. (2011, April). Reasons for information technology adoption and sophistication within manufacturing SMEs. In POMS 22nd Annual Conference: Operations management: The enabling link. Reno, USA, April (Vol. 29).

Goo, J. (2010). Structure of service level agreements (SLA) in IT outsourcing: The construct and its measurement. Information Systems Frontiers, 12(2), 185-205.

Gustafsson, A., Nilsson, L., \& Johnson, M. D. (2003). The role of quality practices in service organizations. International Journal of Service Industry Management, 14(2), 232-244. 
Al-Hawari, M., \& Ward, T. (2006). The effect of automated service quality on Australian banks' financial performance and the mediating role of customer satisfaction. Marketing Intelligence \& Planning, 24(2), 127-147.

Hussain, M., \& Gunasekaran, A. (2002). Management accounting and performance measures in Japanese banks. Managing Service Quality: An International Journal, 12(4), 232-245.

Igbaria, M., \& Tan, M. (1997). The consequences of information technology acceptance on subsequent individual performance. Information \& management, 32(3), 113-121.

Jayawardhena, C. (2004). Measurement of service quality in internet banking: the development of an instrument. Journal of Marketing Management, 20(1-2), 185-207.

Jun, M., \& Cai, S. (2001). The key determinants of internet banking service quality: a content analysis. International journal of bank marketing, 19(7), 276-291.

Kannabiran, G., \& Narayan, P. C. (2005). Deploying Internet banking and e-commerce - case study of a private-sector bank in India. Information Technology for Development, 11(4), 363-379.

KPMG (2015). Mobile banking (2015) https://www.kpmg.com/ UK/en/IssuesAndInsights/ Articles Publications/Documents/PDF/mobile-banking-report-2015.pdf.

Lepmets, M., Mesquida, A. L., Cater-Steel, A., Mas, A., \& Ras, E. (2014). The evaluation of the IT service quality measurement framework in industry. Global Journal of Flexible Systems Management, 15(1), 39-57.

Lee, P. K., Cheng, T. E., Yeung, A. C., \& Lai, K. H. (2011). An empirical study of transformational leadership, team performance and service quality in retail banks. Omega, 39(6), 690-701.

Liu, Y., Chen, Y., \& Zhou, C. (2006, October). Determinants affecting end-user satisfaction of information technology service. In Service Systems and Service Management, 2006 International Conference on (Vol. 1, pp. 478-481). IEEE.

Mwangi, B. J., \& Brown, I. (2015). A decision model of Kenyan SMEs' consumer choice behavior in relation to registration for a mobile banking service: A contextual pPerspective. Information Technology for Development, 21(2), 229-252.

Mikhailov, L., \& Tsvetinov, P. (2004). Evaluation of services using a fuzzy analytic hierarchy process. Applied Soft Computing, 5(1), 23-33.

Kumar Behera, A., Nayak, N. C., Das, H. C., \& Mohapatra, R. N. (2015). An empirical study of the impact of IT on performance in Indian service industries. Global Business and Organizational Excellence, 34(3), 67-78.

Nudurupati, S. S., Bititci, U. S., Kumar, V., \& Chan, F. T. (2011). State of the art literature review on performance measurement. Computers \& Industrial Engineering, 60(2), 279-290.

Park, J., Lee, J., Lee, H., \& Truex, D. (2012). Exploring the impact of communication effectiveness on service quality, trust and relationship commitment in IT services. International Journal of Information Management, 32(5), 459-468.

Pick, J. B., Gollakota, K., \& Singh, M. (2014). Technology for development: Understanding influences on use of rural telecenters in India. Information Technology for Development, 20(4), 296-323.

Shaik, M.N. and Abdul, K.W (2014) "Comprehensive performance measurement and causal-effect decision making model for reverse logistics enterprise," Computers and Industrial Engineering, Vol. 68 , pp. 87-103.

Southern, A., \& Tilley, F. (2000). Small firms and information and communication technologies (ICTs): toward a typology of ICTs usage. New Technology Work and Employment, 15(2), 138-154.

Tanriverdi, H. (2005). Information technology relatedness, knowledge management capability, and performance of multibusiness firms. MIS quarterly, 29(2), 311-334.

Therrien, P., Doloreux, D., \& Chamberlin, T. (2011). Innovation novelty and (commercial) performance in the service sector: A Canadian firm-level analysis. Technovation, 31(12), 655-665.

Vera, J., \& Trujillo, A. (2013). Service quality dimensions and superior customer perceived value in retail banks: An empirical study on Mexican consumers. Journal of Retailing and Consumer Services, 20(6), 579-586. 
Yee, R. W., Lee, P. K., Yeung, A. C., \& Cheng, T. C. E. (2013). The relationships among leadership, goal orientation, and service quality in high-contact service industries: An empirical study. International Journal of Production Economics, 141(2), 452-464.

Zhang, X., Chen, R., \& Ma, Y. (2007). An empirical examination of response time, product variety and firm performance. International Journal of Production Research, 45(14), 3135-3150.

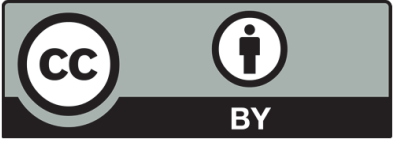

(C) 2017 by the authors; licensee Growing Science, Canada. This is an open access article distributed under the terms and conditions of the Creative Commons Attribution (CC-BY) license (http://creativecommons.org/licenses/by/4.0/). 